\title{
Financial Statement Analysis of Guangzhou Baiyun International Airport Co., Ltd.
}

\author{
Su Ming ${ }^{1}$, Su Lei ${ }^{2, *}$ \\ ${ }^{1}$ Guangdong University of Foreign Studies South China Business College Airport Economic \\ Collaborative Innovation Research Center, Guangzhou, Guangdong, 510545 \\ ${ }^{2}$ Dongguan Shi long Staff Amateur School, Dongguan, Guangdong, 523002
}

Keywords: Baiyun Airport; Financial statements; Cost control; Measures

\begin{abstract}
In recent years, Guangzhou airport economic development is relatively rapid. The infrastructure of Baiyun Airport has been continuously improved and the service level has been further improved. This paper takes the financial statement data of Guangzhou Baiyun International Airport Co., Ltd as the research object in recent five years, which analyzes its financial status. The results of the company's financial statement analysis show that business income keeps stable growth, profitability is strong, cost control is good, but operating capacity, total assets return rate has declined. The author believes that the company should take some measures, such as further improve asset turnover, standardize investment behavior, strengthen procurement management, and reduce labor costs. So it can control the financial risk of Guangzhou Baiyun International Airport Co., Ltd.
\end{abstract}

\section{General Situation of Guangzhou Baiyun International Airport Co., Ltd.}

Guangzhou Baiyun International Airport Co., Ltd. (hereinafter referred to as Baiyun Airport) was established in 2000 and listed in 2003 with a registered capital of about 2 billion yuan. The company's primary business mainly includes air ground passenger, cargo transit services, transportation and warehousing services, aircraft maintenance, commodity retail and so on. The main shareholders of the company are Guangdong Airport Group and Hong Kong Central Settlement Company Limited, of which $51.05 \%$ are held by Guangdong Airport Group, 12.79\% by Guangdong People's Government and $12.79 \%$ by Hong Kong Central Settlement Company Limited. The company consists of Guangzhou Baiyun Advertising Co., Ltd., Guangzhou Baiyun Airport Business Travel Service Co., Ltd., Guangzhou Baiyun Airport Express Line Transportation Co., Ltd., Guangzhou Baiyun International Airport Terminal 2 Management Co., Ltd. and many other subsidiaries. At present, the company has three runways, 01R-19L, 02L-20R and 02R-20L, which can meet the strength requirements of A380 takeoff and landing. The third runway is 3800 meters long and 60 meters wide, and the flight zone grade index is $4 \mathrm{~F}$. In addition, the company also has two terminal buildings, 202 passenger seats, 43 cargo seats, and the total building area of the terminal is more than 1.4 million square meters. In 2017, the passenger throughput of Guangzhou Baiyun International Airport was 65.877 million, ranking third in the country and thirteenth in the world. 


\section{Analysis of Operating Capability of Guangzhou Baiyun International Airport Co., Ltd.}

As can be seen from Table 1, the turnover rate of accounts receivable at Baiyun Airport increased first and then decreased from 2012 to 2017, both rising from 2012 to 2016, and declining in 2017. The turnover rate of accounts receivable reflects the liquidity of enterprises' accounts receivable. The higher the turnover rate of accounts receivable means that the quicker the collection of accounts, the stronger the liquidity of assets, the stronger the short-term solvency, and the less the collection fees and bad debts loss.

Inventory turnover rate reflects the operation status of enterprises in procurement, warehousing, production and sales. The higher turnover rate, the faster liquidation speed and the lower capital occupancy level. Baiyun Airport's inventory turnover rate first increased, then decreased and then increased. Total assets turnover rate is the ratio of net income of main business to total assets. It reflects the utilization efficiency of all assets of an enterprise. Overall, Baiyun Airport is on the rise first and then on the decline. It has been declining in the past three years. This shows that the efficiency of assets management of Baiyun Airport has declined and its operational capacity has been declining, which needs to be paid attention to.

The turnover rate of fixed assets reflects the turnover and utilization efficiency of enterprises' fixed assets. The turnover rate of fixed assets of Baiyun Airport has been increasing in the past six years, which shows that the fixed investment of Baiyun Airport is appropriate and plays its capital effect well.

Table 1 Operating Capacity Analysis of Baiyun Airport Co., Ltd. from 2012 to 2017

\begin{tabular}{|c|c|c|c|c|c|c|}
\hline financial index year & 2012 & 2013 & 2014 & 2015 & 2016 & 2017 \\
\hline Inventory turnover (sub) & 58.32 & 60.72 & 57.70 & 48.71 & 51.33 & 53.26 \\
\hline $\begin{array}{c}\text { Receivable turnover rate } \\
\text { (sub) }\end{array}$ & 7.04 & 8.53 & 8.94 & 9.00 & 9.04 & 8.48 \\
\hline $\begin{array}{c}\text { Current assets turnover rate } \\
\text { (sub) }\end{array}$ & 2.49 & 2.32 & 1.70 & 1.81 & 2.86 & 2.18 \\
\hline $\begin{array}{c}\text { Fixed assets turnover rate } \\
\text { (sub) }\end{array}$ & 0.58 & 0.69 & 0.81 & 0.81 & 0.86 & 0.87 \\
\hline $\begin{array}{c}\text { Total asset turnover rate } \\
\text { (sub) }\end{array}$ & 0.45 & 0.51 & 0.53 & 0.48 & 0.41 & 0.34 \\
\hline $\begin{array}{c}\text { Working Capital Turnover } \\
\text { Rate (sub) }\end{array}$ & -4.86 & 39.58 & 4.03 & 6.10 & -18.40 & -7.58 \\
\hline $\begin{array}{c}\text { Non-current Capital } \\
\text { Turnover Rate (sub) }\end{array}$ & 0.55 & 0.66 & 0.76 & 0.65 & 0.48 & 0.40 \\
\hline
\end{tabular}

Data source: Wind database

\section{Profitability Analysis of Guangzhou Baiyun International Airport Co., Ltd.}

From Table 2, we can see that the operating profit margin of Baiyun Airport has declined in the past six years, except in 2015, the other years are showing an upward trend, which shows that the enterprise has good efficiency and strong profitability. The return on net assets reflects the ability of enterprises to obtain income from their own capital. The overall trend of the return on net assets at Baiyun Airport is consistent with the operating profit margin. Net sales interest rate reflects the level of profitability of business operations. Baiyun Airport net interest rate is also in addition to a decline in 2015, and other years are showing an upward trend, indicating that the level of profitability of business operations is higher. The return on total assets reflects the comprehensive management level of enterprises. Baiyun Airport increased from 2012 to 2015 and decreased from 
2016 to 2017. The product-related factors that lead to the decline of the total asset return rate are the decrease of the price, the rise of raw materials and fuels, and the rise of the financial cost of management expenses, etc. Through the analysis of financial data of annual report, the direct cost and financial cost of Baiyun Airport in 2016 and 2017 are rising, especially the financial cost has increased significantly( Fig. 1). This shows that the decline of the return on total assets is closely related to it.

Table 2 Analysis of the Profitability of Baiyun Airport Co., Ltd. from 2012 to 2017

\begin{tabular}{|c|c|c|c|c|c|c|}
\hline financial index $\quad$ year & 2012 & 2013 & 2014 & 2015 & 2016 & 2017 \\
\hline Return on net assets (\%) & 10.69 & 11.97 & 13.41 & 13.88 & 13.71 & 12.38 \\
\hline Net interest rate on total assets (\%) & 7.61 & 9.46 & 11.01 & 11.07 & 9.26 & 7.95 \\
\hline Net sales interest rate (\%) & 16.93 & 18.49 & 20.93 & 23.04 & 22.57 & 23.68 \\
\hline Operating profit margin (\%) & 24.56 & 25.58 & 28.51 & 31.09 & 30.80 & 32.02 \\
\hline
\end{tabular}

Data source: Wind database

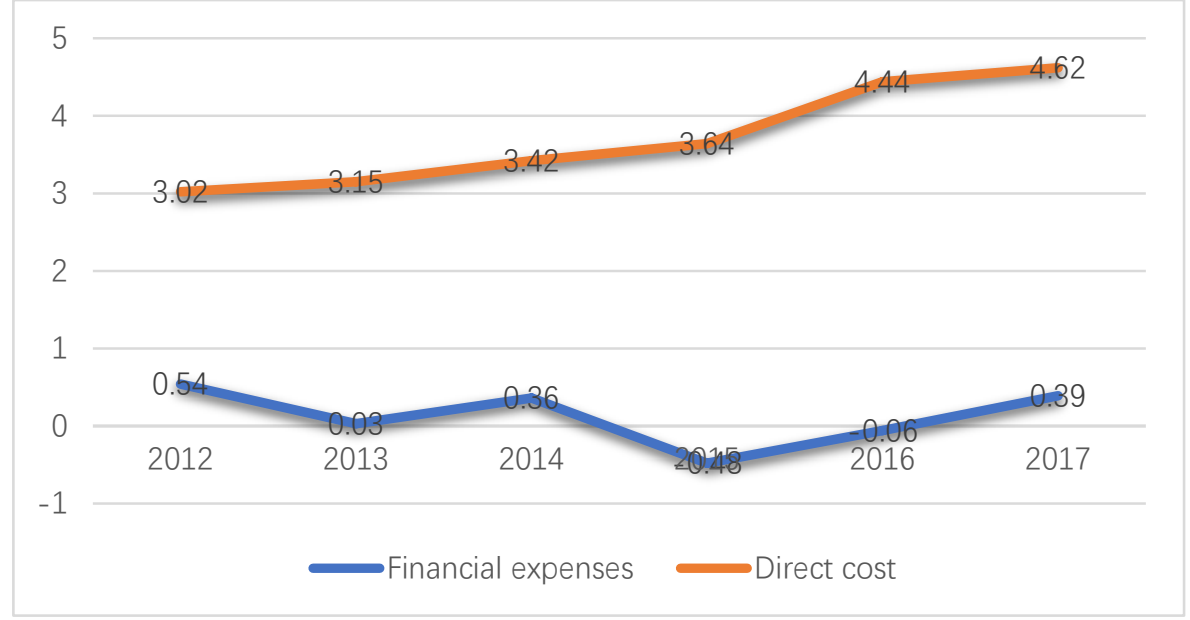

Fig.1 Trend chart of financial cost and direct cost of Baiyun Airport from 2013 to 2017 (unit: 100 million yuan)

\section{Analysis of the solvency of Guangzhou Baiyun International Airport Co., Ltd.}

From Table 3, we can see the solvency of Baiyun Airport in recent years. The ratio of property rights, also known as the debt-to-equity ratio, is the ratio of total liabilities to total owner's equity, reflecting the long-term solvency of enterprises and an important indicator of whether the financial structure of enterprises is stable. Baiyun Airport was 0.37 in 2012. It remained relatively stable from 2013 to 2015. It rose rapidly to 0.64 in 2016, doubled from 2015, and declined in 2017, but it is still higher than 2015. Explain that in 2016 and 2017, Baiyun Airport's liabilities increased, and long-term solvency decreased. It is necessary to control the scale of liabilities and pay attention to the sound structure of funds. Both the current ratio and the quick ratio are indicators that reflect the short-term solvency of the company. The two indicators are in the same trend. The Baiyun Airport current ratio and the quick ratio are both rising from 2012 to 2014 and from 2015 to 2017. It began to show a downward trend, indicating that the short-term solvency of Baiyun Airport gradually increased from 2012 to 2014, and began to decline in 2015. According to the annual report, the decline in the solvency of Baiyun Airport in recent years was mainly due to the investment in the airport expansion project. 
Table 3 Analysis of the solvency of Baiyun Airport Co., Ltd. from 2012 to 2017

\begin{tabular}{|c|c|c|c|c|c|c|}
\hline financial index & 2012 & 2013 & 2014 & 2015 & 2016 & 2017 \\
\hline Property ratio & 0.37 & 0.25 & 0.26 & 0.27 & 0.64 & 0.49 \\
\hline Current ratio & 0.80 & 1.43 & 1.99 & 0.93 & 0.80 & 0.76 \\
\hline Quick ratio & 0.78 & 1.40 & 1.96 & 0.90 & 0.78 & 0.75 \\
\hline
\end{tabular}

Data source: Wind database

\section{Analysis of the main business cost of Guangzhou Baiyun International Airport Co., Ltd.}

The main business cost of Baiyun Airport is mainly composed of labor cost, depreciation expense, direct cost, maintenance fee, water and electricity fee, water and electricity management fee, labor service fee and other operating costs. Labor costs have been increasing in recent years, from 1.139 billion yuan in 2013 to 1.846 billion yuan in 2017, and the proportion of costs is also increasing, from 34.93\% in 2013 to 45.9\% in 2017. Near half of the cost. Depreciation fees have dropped significantly in recent years, from 665 million yuan in 2013, accounting for $20.4 \%$ to 451 million yuan in 2017, accounting for $11.2 \%$. Direct costs mainly refer to material costs, commodity sales costs, etc. Baiyun Airport's direct cost and proportion in recent years are all increasing, from 315 million yuan in 2013, accounting for $9.67 \%$ to 462 million yuan in 2017. The proportion of $11.5 \%$ is an important aspect of Baiyun Airport's cost control. Maintenance costs and utilities, water and electricity management fees are well controlled. In recent years, the overall trend has been a slight downward trend, and both the value and the proportion have declined. Other operating costs have increased and decreased in recent years, with little change. Labor service fees mainly refer to labor outsourcing costs. In recent years, Baiyun Airport labor costs have also been on the rise, from 0.75 billion yuan in 2013, accounting for 2.3\% to 114 million yuan in 2017, accounting for 2.84\%. With the rapid rise of human capital in recent years, high labor costs and labor costs are serious problems that need to be solved in the future operation of Baiyun Airport.

\section{Financial Optimization Measures of Guangzhou Baiyun International Airport Co., Ltd.}

\subsection{Strengthen internal control and increase asset turnover}

The total asset turnover rate of Baiyun Airport in the past three years has declined, indicating that corporate assets have not been effectively utilized. First, it can strengthen the procurement management. Grasping the market dynamics in a timely manner, formulating scientific and reasonable procurement plans in order to avoid excessive procurement, reduce inventory, and improve capital efficiency. Second, it can strengthen the ability to collect accounts receivable. According to the accounts receivable turnover rate indicator in Table 1, the overall collection capacity of Baiyun Airport in recent years has declined. The legal ability can be used to improve the recovery of external debts. Strengthening contract management to ensure that funds and raw materials supply are effectively guaranteed. Finally, it need to revitalize assets to increase asset returns. Regularly check the assets and liabilities of Baiyun Airport, and deal with long-term unused idle assets to improve asset utilization.

\subsection{Improve the financial system and control direct costs}

Managers need to improve the financial management system of Baiyun Airport, establish a financial evaluation system for the company, as well as provide early warning against the company's financial risks. As raw materials and fuels continue to rise, the control of direct costs 
must be strengthened. Firstly, strengthen procurement management, intensive procurement, reduce purchase prices, save procurement costs, and reduce logistics costs. Secondly, strengthen supplier management, establish a supplier screening evaluation mechanism, select high-quality suppliers and carry out strategic cooperation to improve procurement quality and reduce procurement costs. Thirdly, the use of advanced information management systems to strengthen supply chain management and improve efficiency. Optimize the company's air transport, ground transportation services and other operational procedures, simplify the customs declaration and inspection procedures, and improve the efficiency of airport facilities.

\subsection{Reduce labor costs and improve operational efficiency}

In the recent changes in the cost structure of Baiyun Airport, only the two indicators of labor cost and labor cost are increasing in both amount and proportion. The high labor cost is a serious problem that Baiyun Airport must pay attention to. First, labor costs can be controlled by means of outsourcing and purchasing labor dispatch services. Some or part of the business will be outsourced to third-party companies. Third-party companies will provide skills training, pay wage subsidies, bear the cost of outsourcing personnel, reduce the labor costs of Baiyun Airport, and improve the effective utilization of human resources. Secondly, strengthen school-enterprise cooperation, conduct order training, formulate effective talent training programs, improve staff quality, use high-quality talents to improve airport operational efficiency, and reduce airport costs. Third, establish an assessment performance mechanism to improve labor efficiency. Due to the lack of a good performance appraisal mechanism, the enthusiasm of employees is not high, and it is prone to negative absenteeism and waste of human resources. Therefore, it is necessary to establish a strict performance appraisal mechanism for rewards and punishments, strengthen supervision, enhance employee enthusiasm, or improve the use of human resources, and avoid waste of human resources.

\subsection{Standardize investment behavior and reduce financial expenses}

First, it's important to invest with caution and avoid blind investment. Airport construction has the characteristics of large investment, long cycle and slow return; and economic development is cyclical. During the economic boom period, the prices of various production factors are relatively high. At this time, a large amount of investment will cause excessive cost and lower returns. Baiyun Airport needs to conduct a full and detailed investigation, do a good job of feasibility analysis, rational and flexible investment according to the economic situation, reduce investment during the economic boom period, and increase investment during the economic recession. Second, it need to strengthen foreign exchange management. Exchange loss is also one of the risks faced by Baiyun Airport. Baiyun Airport should set up an innovative settlement method to encourage customers to use RMB settlement as much as possible to reduce exchange losses. Third, comprehensive use of various financing methods to reduce financing costs. Fully flexible use of bonds, stocks, bank loans, leasing and other means of financing, combined with the financing costs of various financing methods and the development needs of Baiyun Airport, reasonable financing structure, reduce financing costs. Finally, a reasonable loan saves the cost of borrowing. According to the market prospects and the development of Baiyun Airport, the loan quota and the borrowing period will be adjusted in a timely manner. When there is money, the loan will be repaid in time and the financial interest expense will be reduced.

\section{Acknowledgments}

Foundation projects: This paper is the Guangzhou Social Science Planning Project "Research on 
Improving the Power of Foreign Economic and Trade Development under the Strategic Framework of Guangzhou International Aviation Hub" (16G13); the Guangdong Social Science Planning Project "Research on Guangzhou Airport Economic Development under the Background of Guangdong, Hong Kong and Macau Bay Area Construction" (GD17XYJ27); and the Guangzhou Social Science Planning Project "Research on the Industrial Development Path of Guangzhou Airport Economic Zone" in 2018. (2018GZGJ160) Phased results. Thank you for your support from the Center for Airport Economic Co-operation and Innovation, Guangdong University of Foreign Studies South China Business College.

\section{References}

[1] Civil Aviation Administration of China. 2017 Civil Aviation Airport Production Statistics Bulletin [R]. Beijing: Civil Aviation Administration of China, 2018

[2] Zhang Suhua. On the management of airport cost control [J]. Finance and Economics (Academic Edition), 2015, (20): 115, 178.

[3] Cao Guangrui. Discussion on Financial Internal Control System of State-owned Airport Enterprises [J]. China Chief Accountant, 2014, (10): 148-149

[4] Shi Yunfei. Exploring the Financial Risk Prevention of Airport Enterprises[J].Administrative Assets and Finance,2014,(02):92-93

[5] Yin Shuai. Research on Capital Airport Financial Evaluation System Based on Sustainable Development [D]. Beijing: Beijing Jiaotong University Master thesis, 2012

[6] Chen Juan. Strengthening and improving the financial management of airport in China [J]. Financial Economy, 2010, (24): 157-158

[7] Jiang Bowen. Discussion on Improving the Efficiency of Financial Operation of Western Airport Enterprise Groups[J].International Business Finance,2010,(24):57-59 